\title{
O Brasil e a integração sul-americana
}

\section{Camilo Pereira Carneiro \& Milene Meneghetti Bruhn}

\section{Introdução}

Na última década do século XX, a América do Sul testemunhou a emergência de um processo de integração regional que modificou as relações entre os países do subcontinente. O mencionado processo emergiu em um contexto internacional marcado pelo Novo Regionalismo ${ }^{1}$, que foi testemunhado nos diferentes continentes e era movido pela necessidade dos Estados nacionais de ampliar o espaço de circulação de suas mercadorias em um mercado capitalista e globalizado.

Consolidado ao fim da Guerra Fria, o Novo Regionalismo foi fruto do processo de globalização e dos efeitos imprevisíveis deste sobre as relações multilaterais. Caracterizou-se pelo surgimento e fortalecimento de blocos regionais de países e pela consolidação de diversas áreas de livre comércio em todo o globo. Na América do Sul, especificamente, emergiram neste período diferentes projetos de integração regional como o MERCOSUL (Mercado Comum do Sul), criado em 1991, e a UNASUL (União de Nações Sul-Americanas), implementada em 2008.

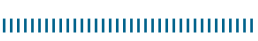

1 De acordo com Borges (2014), o Novo Regionalismo teve início em 1985 e prossegue até os dias atuais, fazendo parte do que se considera a terceira fase do regionalismo, na qual o papel da globalização e seus efeitos imprevisíveis sobre as relações multilaterais estimularam a criação de novos blocos regionais de comércio ao redor do planeta.
A aproximação entre Brasil e Argentina conduziu à criação de uma zona de paz no Cone Sul, os dois países iniciaram uma relação de confiança mútua e deram origem a instrumentos jurídicos e operacionais que permitiram que o comércio intrazona fosse elevado de US\$4,1 bilhões em 1990 para US\$20,5 bilhões em 1997. O desvio de comércio foi benéfico para os países do MERCOSUL, incapazes de se impor frente à competitividade sistêmica global. (CERVO; BUENO, 2008).

A emergência (em alguns casos a consolidação) dos blocos regionais gerou benefícios que não se limitaram apenas à seara econômica e que promoveram a extensão de direitos dentro das áreas dos blocos. No MERCOSUL, por exemplo, os países membros criaram acordos referentes a temas como educação (PEIBF e UNILA), cidades gêmeas (acordos sobre localidades vicinais fronteiriças) e circulação de pessoas (aceitação de documento de identificação civil em viagens internacionais dentro da América do $\mathrm{Sul}^{2}$ ), entre outros.

Em meio ao fortalecimento da integração regional sul-americana, o governo brasileiro

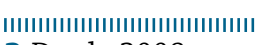

2 Desde 2008, nas viagens realizadas entre os países do bloco os turistas dos países membros e associados do MERCOSUL são autorizados a apresentar a cédula de identidade civil (com menos de 10 anos de expedição). Não há obrigatoriedade de apresentação de passaporte, nem é exigido visto de entrada.

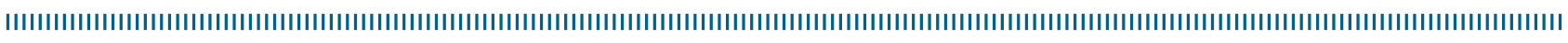
Como citar este artigo:

CARNEIRO, Camilo Pereira \& BRUHN, Milene Meneghetti. “O Brasil e a integração sul-americana”. In: RÜCKERT, A. A.; SILVA, A. C. P. da; SILVA, G. de V. (Orgs.). Geografia Política, Geopolítica e Gestão do Território: integração sul-americana e regiões periféricas. Porto Alegre: Editora Letra1, 2018, p. 68-84 
passou a promover iniciativas no intuito de assegurar ao país o papel de líder regional. Nesse contexto, no ano 2000 foi criada a IIRSA (Iniciativa para a Integração da Infraestrutura Regional Sul-Americana), um programa que abrange governos de doze países da América do Sul, criado com o objetivo de promover a integração física do subcontinente (por meio de obras de infraestrutura de transporte, energia e telecomunicações) e de estimular a integração política, econômica e cultural na América do Sul.

Idealizada e criada durante o governo de Fernando Henrique Cardoso (1995-2002), a IIRSA, que a partir de 2009 seria incorporada à UNASUL por meio do COSIPLAN (Conselho SulAmericano de Infraestrutura e Planejamento), teve continuidade e foi uma das principais ferramentas da política externa brasileira ao longo dos governos Lula da Silva (2003-2010) e no primeiro governo Dilma Rousseff (2011-2014). A estratégia de inserção internacional do Brasil, na qual a IIRSA-COSIPLAN estava inserida, foi moldada em meio a um esquema de corrupção revelado pela operação da Polícia Federal do Brasil denominada Lava Jato - do qual faziam parte grandes multinacionais brasileiras (os detalhes da operação serão abordados na seção 5 do presente trabalho).

No intuito de apresentar os diferentes momentos do processo de integração sulamericano, o presente artigo inicia com um breve histórico das iniciativas de integração no subcontinente, em seguida aborda o papel do Brasil como líder regional, a estratégia de internacionalização das empresas brasileiras e os obstáculos para a integração sul-americana. Por fim, traz uma análise dos impactos da mudança nos rumos da política externa do Brasil sob o governo Temer e o papel da China, país que vem emergindo como novo ator protagonista na integração sul-americana.

\section{Iniciativas de integração Sul-Americana}

As primeiras iniciativas de integração envolvendo países da América do Sul tiveram, na realidade, uma abrangência latino-americana e remontam o período pós-Segunda Guerra Mundial, quando da criação da CEPAL (Comissão Econômica para a América Latina e Caribe) e, posteriormente, da ALALC (Associação LatinoAmericana de Livre Comércio). A CEPAL foi criada em 1948 pelo Conselho Econômico e Social das Nações Unidas como uma comissão econômica da ONU, com atribuição principal de incentivar a cooperação econômica entre seus membros.

A ALALC, por sua vez, surgiu em 1960, como uma tentativa de criação de uma área de livre comércio formada por Argentina, Brasil, Chile, México, Paraguai, Peru, e Uruguai. A iniciativa visava a formação de uma zona de livre comércio que deveria iniciar em 31 de dezembro de 1972, ocorrendo de forma gradual. No entanto, a ALALC não iria atingir seu objetivo.

No decorrer da década de 1970, surgiram algumas iniciativas de integração sub-regional na América do Sul, com destaque para o Tratado de Cooperação Amazônica, criado em 1978 pelos países da Bacia Amazônica (Bolívia, Brasil, Colômbia, Equador, Guiana, Peru, Suriname e Venezuela), com a finalidade de promover ações conjuntas para o desenvolvimento econômico da região.

Já no ano de 1980 uma nova organização foi criada na América Latina: a ALADI (Associação Latino-Americana de Integração). Com sede estabelecida em Montevidéu, a nova organização foi criada para substituir e dar prosseguimento à ALALC e nasceu com o objetivo de promover a integração da América Latina, bem como o desenvolvimento econômico e social da região. Composta por treze países-membros (Argentina, Bolívia, Brasil, Chile, Colômbia, Cuba, Equador, México, Panamá, Paraguai, Peru, Uruguai e Venezuela), a ALADI possui quatro objetivos principais: a) eliminação gradativa dos obstáculos ao comércio recíproco dos países membros; b) impulsão de vínculos de solidariedade e cooperação entre os povos latino-americanos; c) promoção do desenvolvimento econômico e social da região; e d) criação de uma área de preferências econômicas, tendo como objetivo final o estabelecimento de um mercado comum latino-americano. 
Embora não tenha deixado de existir, a ALADI perdeu peso e importância ao longo da década de 1980 e viria a ficar às sombras de um novo bloco regional, quando, em 1991, Argentina, Brasil, Paraguai e Uruguai celebraram o Tratado de Assunção para a constituição do MERCOSUL. O novo bloco alterou profundamente as relações comerciais no Cone Sul. Nesse sentido, Garcia (2005) destaca que logo nos primeiros anos, entre 1991 e 1997, o comércio regional intrazona cresceu aproximadamente $312 \%$.

Na esteira do Novo Regionalismo, caracterizado, sobretudo, pelo Regionalismo Aberto ${ }^{3}$, que se espalhava pelo planeta, o MERCOSUL começou a se consolidar e seus membros passaram a adensar suas relações. Concomitantemente, ao norte do continente, os Estados Unidos passaram a vislumbrar a ideia de expandir seu mercado para toda a América Latina (com exceção de Cuba). No decorrer da década de 1990, em meio à possibilidade de concretização de novos acordos de livre comércio capitaneados pelos Estados Unidos (proposta de criação da ALCA, em 1994) e pela União Europeia (acordo de cooperação firmado em 1995), o Brasil e seus parceiros do MERCOSUL optaram pelo aprofundamento dos esquemas existentes.

Ao longo dos governos de Fernando Collor (1990-1992) e Fernando Henrique Cardoso (1995-2002), o Brasil adotou medidas de cunho neoliberal pautadas no Consenso de Washington e incentivadas pelo FMI e pelo Banco Mundial. As privatizações e a desindustrialização do país foram o resultado de tais políticas. Os referidos governos demonstraram especial preocupação com o aumento das exportações de commodities, tendo privilegiado setores mais competitivos da economia no cenário internacional.

Durante o ano 2000, o Brasil passou a adotar em sua política externa uma estratégia inspirada na antiga ideia do presidente Fernando Henrique

||||||||||||||||||||||||||||||||||||

$3 \mathrm{O}$ Regionalismo Aberto corresponde a um processo de crescente interdependência em nível regional, promovida por acordos preferenciais de integração e por outras políticas, num contexto de liberalização e desregulação capaz de fortalecer a competitividade dos países de uma determinada região e, na medida do possível, constituir a formação de blocos econômicos.
Cardoso, de dissociar o conceito de América do Sul (geograficamente mais inclusivo) daquele de América Latina (mais ambíguo). Naquele ano, na reunião de presidentes da América do Sul, ocorrida em Brasília (onde pela primeira vez na história, os chefes de governo dos doze países do subcontinente trataram de temas como democracia, comércio, infraestrutura, tráfico de drogas, informação, conhecimento e tecnologia), nasceu a IIRSA. O evento serviu para fortalecer o processo de integração sul-americano e gerou um novo ponto de apoio, de caráter sub-regional, para a aproximação entre os países da região. (ALMEIDA, 2002).

O processo de integração da América do Sul foi aprofundado no início do século XXI em meio a uma conjuntura política favorável (diversos países da região possuíam governos de esquerda e centroesquerda) e em 2008, na ocasião da III Cúpula de Chefes de Estado e de Governo, foi estabelecido o Tratado Constitutivo da UNASUL, por meio do qual os membros do MERCOSUL e da Comunidade Andina de Nações (CAN) uniram-se ao Chile, à Guiana e ao Suriname, no intuito de constituir uma zona de livre comércio (Mapa 1).

Desde seu surgimento, a UNASUL passou a desenvolver um papel importante no fortalecimento da democracia na América do Sul, tendo atuado na mediação de tensões regionais (crise separatista dos departamentos não-andinos da Bolívia, em 2008; crise entre Colômbia e Venezuela, em 2010; apoio à ordem constitucional e democrática do Equador durante a sublevação da Polícia Nacional, em 2010) e na elaboração de medidas de fomento à confiança e segurança pelo Conselho de Defesa Sul-Americano. (BRASIL, 2017 a).

\section{Entraves no processo de integração regional da América do Sul}

O processo de integração sul-americano, iniciado no final do século XX, vem sendo marcado por uma série de entraves, como a coexistência de diferentes blocos na região (efeito spaghetti bowl), os numerosos obstáculos ao livre comércio, medidas protecionistas implantadas pelos 
Mapa 1. Principais agrupamentos regionais sul-americanos.

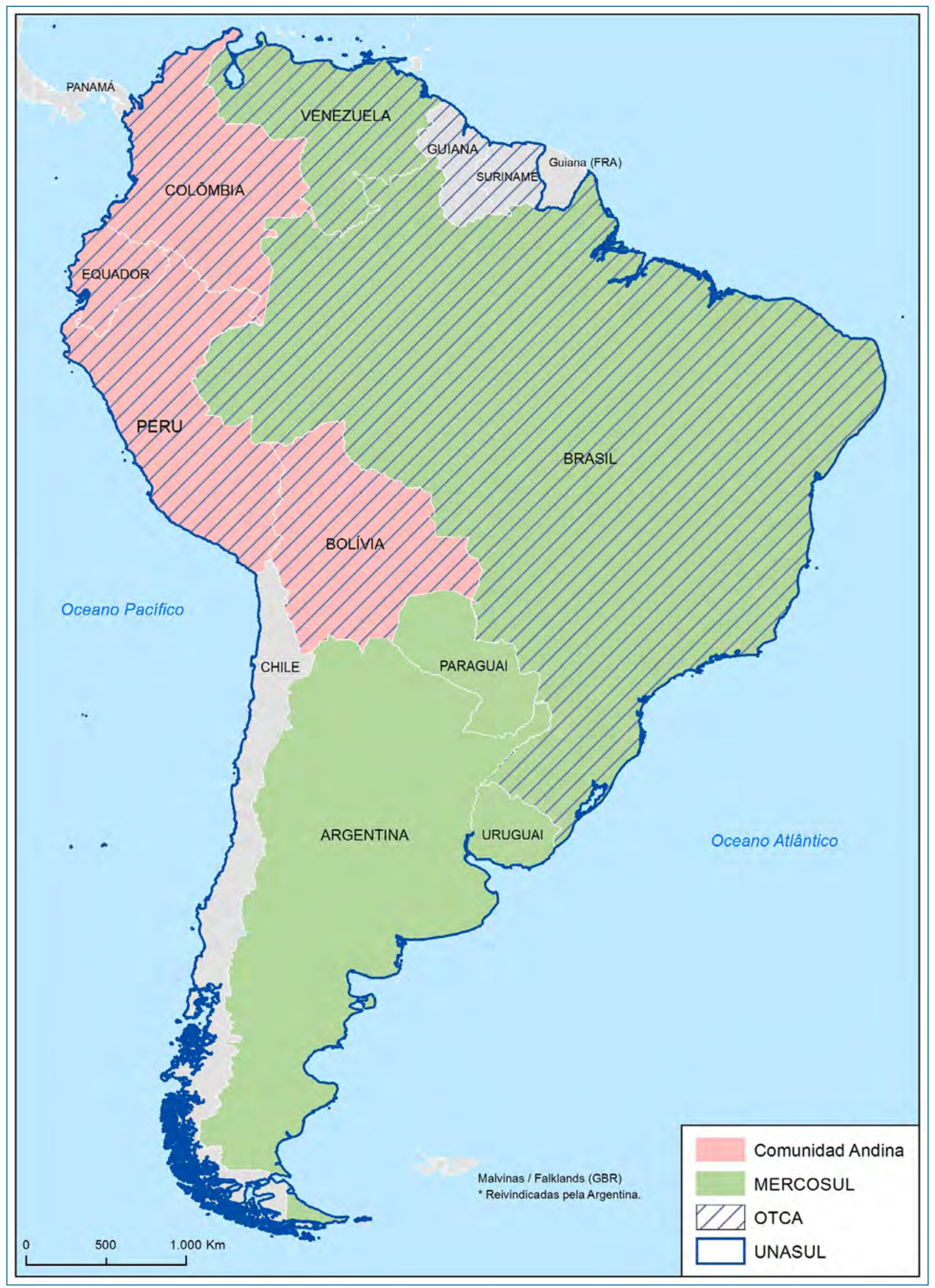

Autor: PEREIRA CARNEIRO, 2017. 
países da região, descontinuidade de projetos de integração e a presença estadunidense, que se dá tanto por meio de acordos bilaterais de comércio com alguns países latino-americanos, como por meio de tropas militares instaladas ao sul do Rio Grande.

As deficiências do processo de integração podem ser percebidas ao se analisar o funcionamento do MERCOSUL, cujo objetivo original era a promoção de uma zona de livre circulação de bens e serviços, com uma coordenação de tarifas e políticas comerciais. Apesar dos ideais vislumbrados na constituição do bloco - a criação de um mercado comum -, o MERCOSUL hoje pode ser classificado como uma união aduaneira imperfeita. (PEREIRA CARNEIRO, 2016).

Cabe destacar que a finalidade de uma união aduaneira é atrair investimentos produtivos para o interior dos países que a compõem. As empresas que se instalam nos países do bloco devem ter benefícios como: mercado consumidor ampliado, gerado pela regra de livre comércio; e proteção alfandegária comum contra a concorrência de empresas de fora do bloco.

Os inúmeros entraves ao livre comércio entre os países membros estão por trás de críticas direcionadas ao bloco. Nesse sentido, alguns autores chegam até mesmo a considerar o MERCOSUL apenas uma zona de livre comércio. De acordo com Caballero (2012), o MERCOSUL opera mais como uma zona de livre comércio do que como uma união aduaneira. O processo para a concretização de políticas comuns e para a livre circulação de mercadorias em um território único tem sido lento. Ao mesmo tempo, as barreiras comerciais não desapareceram e o diminuto avanço no aprofundamento do MERCOSUL tem como principais responsáveis os maiores países do bloco: Brasil e Argentina.

É importante ressaltar que as barreiras à entrada de mercadorias dos países membros não são o único obstáculo no aprofundamento do MERCOSUL. A circulação de pessoas também encontra empecilhos causados pela burocracia. Um exemplo é o trânsito de automóveis entre países do bloco, dificultada em razão da exigência de documentos como o seguro para veículos em área internacional (denominado carta verde) e das diferenças entre as legislações de trânsito dos países, que geram problemas aos condutores. (PEREIRA CARNEIRO, 2016).

Além de suas limitações e de sua morosidade, o processo de integração sul-americano também tem recebido críticas pela falta de diálogo entre os proponentes dos projetos governamentais (como os da IIRSA-COSIPLAN, por exemplo, que serão tratados no tópico 4.1 do presente trabalho) e as populações atingidas. Os referidos projetos vêm sendo desenvolvidos com uma série de imposições por parte dos governos nacionais às populações das localidades onde são materializados.

\section{O Brasil como líder regional}

Em função de sua dimensão territorial, sua economia, sua população e seu poder militar, o Brasil se destaca na América Latina, sobretudo na América do Sul, podendo ser classificado, de acordo com a terminologia própria do campo das Relações Internacionais, como uma potência regional, que exerce poder e influência sobre sua região geográfica. De acordo com Moniz Bandeira (2008), o Brasil estaria apto a aspirar a posição de potência regional. O referido autor considera que três fatores potencializam um país a almejar a posição de potência em uma hierarquia entre Estados: a extensão territorial, o poder econômico e o poder militar ${ }^{4}$. Características que existem no Brasil desde a metade do século XIX.

No decorrer do segundo governo Lula da Silva (2007 a 2010) e no primeiro governo Dilma Rousseff (2011 a 2014), em meio ao bom momento da economia brasileira, alavancada pela alta nos preços das commodities, a influência do Brasil espalhou-se para outras regiões do planeta e o país passou a ser classificado como uma potência emergente. Cabe destacar que com a divulgação da descoberta do pré-sal pela Petrobras, em 2006,

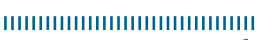

4 Em 2017, o Brasil era o $6^{\circ}$ país em população, o $5^{\circ}$ em extensão territorial, possuía o $9^{\circ} \mathrm{PIB}$, além de ser o $15^{\circ}$ em poder militar no mundo (e o primeiro da América Latina), de acordo com o ranking elaborado pela Global Firepower (2016). 
o governo brasileiro passou a nutrir grandes expectativas de crescimento econômico e social. No entanto, o cenário internacional se alterou a partir de 2014, quando o país mergulhou em uma crise político-econômica e passou a sentir os efeitos da queda do preço internacional do petróleo. É importante ressaltar o peso das commodities na pauta de exportações brasileira. Em 2015, os principais produtos exportados pelo Brasil eram: soja em grãos $\left(1^{\circ}\right)$; minério de ferro $\left(2^{\circ}\right)$; e petróleo e derivados $\left(3^{\circ}\right)$. (AVISITE, 2015).

Embora a situação político-econômica venha impactando profundamente a atuação do país no cenário internacional, o Brasil segue entre as dez principais economias do mundo e possui a sexta maior população. Os números comprovam o peso do Brasil frente aos vizinhos sul-americanos. O país possui o maior PIB entre os membros do MERCOSUL (plenos e associados), além de conter quase metade da população do bloco. Todavia, o peso demográfico e econômico não garante ao país bons números em outros índices. O país não figura nas primeiras posições em quesitos como distribuição de riqueza (PIB per capita) e desenvolvimento humano (IDH), como demonstrado na tabela 1 .
A geografia também garante ao país uma vantagem perante os vizinhos. Por compartilhar fronteira com dez países, o Brasil desfruta de considerável potencial para articular iniciativas em defesa dos interesses sul-americanos. Não obstante, Guimarães (2002) ressalta o fato de que os Estados Unidos configuram um grande desafio para a política externa brasileira, tendo em vista que o país está dentro da área de influência estadunidense.

No decorrer da década de 1980, a política externa brasileira passou a ser direcionada aos países latino-americanos. Nesse contexto, o Brasil começou a desempenhar um papel de protagonista nos processos simultâneos de formação de espaços econômicos integrados na América do Sul (Tratado de Cooperação Amazônica, integração Brasil-Argentina e MERCOSUL), de busca pela reinserção do subcontinente na economia global e por um novo papel desempenhado por si próprio no Sistema Internacional. (ALMEIDA, 2002).

A partir do governo Lula da Silva, o Brasil começou a focar as negociações comerciais com vistas a uma maior aproximação com os países emergentes. Nesse sentido, o país passou a privilegiar as relações com os Estados vizinhos

Tabela 1. PIB, População e IDH dos países do MERCOSUL (2016).

\begin{tabular}{|c|c|c|c|c|c|}
\hline País & & $\begin{array}{l}\text { PIB nominal em } \\
\text { milhões de US\$ }\end{array}$ & $\begin{array}{c}\text { PIB (nominal) per capita } \\
\text { em US\$ }\end{array}$ & População (milhares) & IDH \\
\hline & Brasil & 1.796.187 & 8.650 & 207.848 & 0,754 \\
\hline & Argentina & 545.866 & 12.449 & 43.417 & 0,827 \\
\hline & Paraguai & 27.441 & 4.080 & 6.639 & 0,693 \\
\hline & Uruguai & 52.420 & 15.221 & 3.432 & 0,795 \\
\hline & Bolívia* & 33.806 & 3.105 & 10.725 & 0,674 \\
\hline & Venezuela** & 371.337 & 9.258 & 31.108 & 0,767 \\
\hline MEF & OSUL (Membros) & 2.827 .057 & $8.793,833$ & 303.169 & 0,752 \\
\hline & Peru & 192.094 & 6.046 & 31.377 & 0,740 \\
\hline & Chile & 247.028 & 13.793 & 17.948 & 0,847 \\
\hline & Colômbia & 282.463 & 5.806 & 48.229 & 0,727 \\
\hline 준 & Equador & 97.802 & 5.969 & 16.144 & 0,739 \\
\hline MER & DSUL (Associados) & 819.387 & $7.903,5$ & 113.698 & 0,763 \\
\hline
\end{tabular}

*Em processo de adesão como Estado membro.

** Os dados do PIB nominal per capita da Venezuela correspondem a estimativas do FMI

Fontes: Banco Mundial; FMI; PNUD. Organização: Bruhn, 2017. 
através de medidas que visavam o fortalecimento do MERCOSUL. Durante seu governo, Lula da Silva defendeu a aproximação política, social e cultural entre os países sul-americanos. $\mathrm{O}$ expresidente percebia no bloco um ator com papel estratégico na integração regional. (VIGEVANI; CEPALUNI, 2007).

\section{Desafios ao aprofundamento do MERCOSUL}

Segundo Becard (2009), no início do governo Lula da Silva, o aprofundamento do MERCOSUL encontrou obstáculos nas assimetrias estruturais existentes entre seus membros. $\mathrm{O}$ aprofundamento teria sido constrangido em função de uma preocupação de que a liderança cooperativa do Brasil não fosse entendida por seus parceiros como uma espécie de subimperialismo e que a defesa da autonomia não fosse transformada em hostilidade perante os Estados Unidos.

As assimetrias entre as economias mais fracas e as mais fortes do MERCOSUL chegaram a gerar tensões no bloco, motivadas, sobretudo, por descontentamentos de paraguaios e uruguaios. No intuito de solucionar o problema e diminuir as assimetrias entre as economias mais poderosas e as mais fracas, em 2007 foi criado o FOCEM ${ }^{5}$ (Fundo de Convergência Estrutural do MERCOSUL), no qual $70 \%$ dos recursos são entregues pelo Brasil, 28\% pela Argentina, 2\% pelo Uruguai e $1 \%$ pelo Paraguai. Na contrapartida, os maiores beneficiados são o Paraguai (que recebe $48 \%$ dos recursos) e o Uruguai (que conta com $32 \%$ dos fundos).

A participação do Brasil no FOCEM compôs parte da estratégia brasileira para a América do Sul durante a década de 2000, que consistia no aumento dos investimentos diretos em países vizinhos como o Peru, por exemplo. No intuito

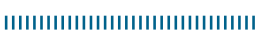

5 Previsto originalmente para terminar em 2015, o FOCEM foi renovado por dez anos. O fundo financia projetos de energia, transportes, integração produtiva e educação, privilegiando os países mais pobres do bloco. Pelo acordo que rege o funcionamento do fundo, anualmente, o Brasil deve fornecer US\$ 70 milhões, Argentina e Venezuela (desde sua entrada, em 2012) US\$ 27 milhões cada, o Uruguai US\$2 milhões e o Paraguai US\$1 milhão. de concretizar uma cooperação que possibilitasse uma maior inserção nos mercados da Ásia/Pacífico, os investimentos diretos do Brasil no Peru passaram de aproximadamente US $\$ 47$ milhões, em 2003, para mais de US $\$ 1$ bilhão no início de 2010. Esse aumento estava vinculado à atuação de multinacionais brasileiras como Odebrecht, Petrobras, Vale e Votorantim, que no referido período participavam de projetos de grande envergadura no território peruano. (DUARTE, 2012).

É importante ressaltar que os grandes investimentos do Brasil nos países vizinhos não dirimiram o protecionismo na América do Sul. Embora formalmente tenham concordado com o aprofundamento da integração regional, os países do MERCOSUL não se comprometeram com o banimento do uso de barreiras para corrigir possíveis desequilíbrios no comércio regional. Apesar dos esforços do governo brasileiro, o bloco e seus associados - Bolívia, Chile, Colômbia, Equador e Peru - não conseguiram fechar o pacto de não adoção de medidas protecionistas entre si.

Não obstante os reveses no âmbito das liberdades de comércio, Almeida (2002) afirma que o MERCOSUL contribuiu para a estabilidade democrática na América do Sul, para o aumento da interdependência recíproca das economias do subcontinente e, acima de tudo, para realçar a capacidade de barganha da América Latina no cenário internacional.

Ainda que sofra com medidas protecionistas e receba uma grande quantidade de críticas, em especial por parte da grande mídia brasileira, o MERCOSUL configura um importante mercado para os produtos brasileiros, sobretudo os manufaturados. Em 2015, os cinco principais destinos dos produtos brasileiros foram China (18\%), Estados Unidos (13\%), Argentina (6,6\%), Países Baixos (4\%) e Alemanha (3,3\%), que, juntos, geravam quase $50 \%$ das receitas oriundas das exportações do país. Por sua vez, as importações brasileiras são provenientes, em grande medida, dos países que também são os que mais compram do Brasil: China (18\%), Estados Unidos (15\%), Alemanha (6,2\%), Argentina (6\%) e Coreia do Sul (3,2\%). (OEC, 2017). 
Ao longo dos anos, o Brasil tem acumulado um significativo superávit comercial com a China e com o MERCOSUL. Contudo, cabe destacar a diferença em relação ao tipo de produto exportado pelo Brasil: enquanto os principais compradores (China e UE) adquirem matérias-primas (commodities, sobretudo soja e minérios), os países vizinhos Argentina, Paraguai, Uruguai, Venezuela, Bolívia, etc. - adquirem bens industrializados. Ou seja, o parque industrial brasileiro tem no MERCOSUL um mercado cativo de suma importância.

\section{Estratégia de internacionalização de empresas brasileiras}

Ao longo dos governos Lula da Silva (20032010) e do primeiro governo Dilma Rousseff (2011-2014), alguns grupos econômicos foram escolhidos como vetores do projeto de um Brasil líder regional. A estratégia levava em conta a internacionalização de empresas brasileiras. Nesse sentido, o Banco Nacional de Desenvolvimento Econômico e Social (BNDES) foi um grande propulsor de transnacionais brasileiras - empresas como BRF, JBS, Odebrecht, Andrade Gutierrez, Queiroz Galvão, Camargo Corrêa, OAS, Vale, Embraer, Marcopolo, entre outras. Os setores mais contemplados pelos financiamentos do BNDES no exterior foram: construção civil, mineração, exportação de carnes, fabricação e exportação de aviões e exportação de ônibus.

Dentre os setores mencionados, o da construção civil recebeu atenção especial por parte do banco. De acordo com Rodriguez (2017), entre 1998 e 2015, o BNDES teria financiado R $\$ 14$ bilhões para as principais empreiteiras brasileiras realizarem obras no exterior. A tabela 2 traz a descrição dos recursos liberados às empreiteiras no modelo pós-embarque, denominação do BNDES para os financiamentos na área de exportação. O montante faz parte do total aprovado, os recursos eram desembolsados de acordo com o cronograma de cada obra.

Apesar dos vultosos recursos destinados ao setor da construção civil, cabe destacar o papel do BNDES em outros setores. No setor metal-
Tabela 2. Financiamentos do BNDES na área de exportação para as principais empreiteiras brasileiras (1998 e 2015)

\begin{tabular}{lc}
\hline Empresa & Total financiado \\
\hline Odebrecht & $\mathrm{R} \$ 9.778 .411 .902,00$ \\
Andrade Gutierrez & $\mathrm{R} \$ 2.875 .354 .488,00$ \\
Camargo Corrêa & $\mathrm{R} \$ 627.719 .298,00$ \\
Queiroz Galvão & $\mathrm{R} \$ 533.846 .458,00$ \\
OAS & $\mathrm{R} \$ 216.256 .636,00$ \\
\hline Total & $\mathbf{R} \$ \mathbf{1 4 . 0 3 1 . 5 8 8 . 7 8 2 , 0 0}$ \\
\hline & Fonte: RODRIGUEZ, 2017.
\end{tabular}

mecânico, por exemplo, a Marcopolo, fabricante brasileira de carrocerias de ônibus, teve no banco um importante financiador de suas exportações. Desde 2003, os empréstimos do BNDES têm permitido a ampliação do mercado da empresa. Atualmente, seus principais consumidores são o México, a Argentina, a Bolívia, o Chile e a África do Sul.

Os financiamentos do BNDES também foram significativos para a Embraer - uma das cinco maiores montadoras de aviões do mundo. Entre 2009 e 2014, a empresa recebeu 6 bilhões de dólares em financiamentos do banco, chegando a compor, em 2014, junto com a Odebrecht, 81\% de todo crédito enviado para o exterior pelo BNDES.

No setor de exportação de carnes, o BNDES financiou, em 2009, a fusão da Sadia e da Perdigão, que deram origem à Brasil Foods (BRF). A operação envolveu uma injeção de cerca de $\mathrm{R} \$ 400$ milhões iniciais. Desde então, a empresa tem mantido a parceria com o banco. Em 2013, o BNDES autorizou a contratação de $\mathrm{R} \$ 2,5$ bilhões para uma expansão das suas capacidades. Com a contribuição do BNDES, a empresa conseguiu se internacionalizar e tornar-se uma das maiores de seu ramo no mundo, estando presente hoje em mais de 150 países.

Ainda no setor de exportação de carnes, o grupo JBS (que atualmente controla marcas como Seara, Friboi, Swift, Vigor, Doriana e Do Chef) foi, sobretudo a partir de 2007, impulsionado pelo BNDES. Entre 2007 e 2010, foram quase $\mathrm{R} \$ 5$ bilhões injetados na empresa. Após sua internacionalização, com a aquisição da Swift, em 2007, o grupo JBS se tornou a maior empresa do mundo de alimentos de origem bovina e aumentou seu faturamento anual de $\mathrm{R} \$ 4$ bilhões, 
em 2006, para mais de $\mathrm{R} \$ 170$ bilhões em 2016. (ALVARENGA; GAZZONI, 2017).

Apesar do BNDES ter financiado empresas de diferentes setores, Hirt (2014) ressalta que durante os dois governos de Lula da Silva e o primeiro governo Dilma Rousseff, o maior investimento do banco foi destinado a um conjunto de grandes empreiteiras (em especial, Odebrecht, Andrade Gutierrez, Camargo Corrêa, Queiroz Galvão e OAS) ligadas não apenas ao setor de construção civil, como também aos setores de mineração, metalúrgico e energético. As referidas empreiteiras passaram a realizar projetos em diversos países da América Latina e da África.

Em pesquisa realizada sobre a atuação do BNDES no exterior, Hirt (2014) destacou os países que de 1995 (governo de Fernando Henrique Cardoso) até 2012 mais receberam obras financiadas pelo banco: Angola (43); República Dominicana (13); Argentina (11); Venezuela (6); Cuba (5); Equador (4); Paraguai (2); Bolívia (1); Moçambique (1); e Peru (1). Cabe destacar que todas as obras foram realizadas em países africanos e latino-americanos, o que demonstra a intenção do governo federal de aumentar a influência do Brasil no Atlântico Sul. A pesquisa corrobora a idéia de que a estratégia brasileira no projeto de potência do hemisfério Sul teve na IIRSA-COSIPLAN uma das principais ferramentas.

\section{A IIRSA-COSIPLAN e a estratégia brasileira para a América do Sul}

Criada no ano 2000, em meio à tentativa do governo brasileiro de ampliar sua influência sobre os países da América do Sul, a IIRSA possibilitou a implementação de projetos de infraestrutura nos setores de transportes, energia e telecomunicações. Financiada pelo BNDES, pelo Banco Interamericano de Desenvolvimento (BID), pela Corporação Andina de Fomento (CAF), e pelo Fundo Financeiro para Desenvolvimento da Bacia do Prata (FONPLATA), a IIRSA teve os seus projetos de integração física absorvidos pelo COSIPLAN, órgão da UNASUL, em 2009. (SCHEIBE, 2013).
Na sua origem, a IIRSA-COSIPLAN deveria ter a função de ser uma articuladora dos blocos existentes na América do Sul, onde a infraestrutura iria servir para incentivar o desenvolvimento econômico dos países da região. (SCHMIED, 2007). Idealizados com o objetivo de facilitar a integração territorial, os projetos da iniciativa possibilitariam a circulação transfronteiriça por meio da construção de pontes, rodovias e ferrovias, além disso, também havia a preocupação de promover a interconexão energética, intensificando as relações entre os países sul-americanos.

Atualmente, a IIRSA-COSIPLAN conta com nove Eixos de Integração e Desenvolvimento (os EIDs), nos quais são desenvolvidos os projetos. Os eixos contemplam $97,7 \%$ do território sul-americano (COSIPLAN, 2017b). Juntos, os eixos reúnem cerca de 600 projetos, com investimentos estimados em US\$ 182 bilhões. (COSIPLAN, 2017a).

Os projetos da iniciativa estão inseridos em um processo de construção das conexões territoriais promovido pela integração competitiva em curso no território multinacional da América do Sul que favorece os focos exportadores, interligando pontos da fronteira às áreas metropolitanas e aos portos. A IIRSA-COSIPLAN promove novas articulações e conexões entre regiões que se beneficiam e outras que são excluídas pela integração competitiva em um processo de internacionalização de territórios-rede transnacionais e de reconcentração das atividades industriais nas regiões mais competitivas, como aquelas localizadas no núcleo geoeconômico do MERCOSUL. A melhoria e a expansão das infraestruturas previstas pela IIRSA-COSIPLAN são de interesse do Estado brasileiro, uma vez que tais obras abrem e consolidam novos mercados para grandes empresas brasileiras, que também poderão contar com os mercados dos países da América do Sul para escoar seus produtos. (SCHEIBE, 2013).

Os líderes políticos envolvidos nos projetos afirmam que os mesmos promovem a integração e o desenvolvimento de regiões mais afastadas e isoladas. Todavia, cabe destacar que alguns projetos estão previstos tanto na IIRSA-COSIPLAN como 
no PAC (Programa de Aceleração do Crescimento), o que evidencia a falta de diálogo entre os gestores dos projetos e os membros do governo brasileiro.

Além do problema da falta de interação entre os gestores dos projetos e as autoridades de Brasília, Porto-Gonçalves e Quental (2012) destacam que as obras da iniciativa também têm como objetivo atender a crescente demanda por commodities na Ásia (China em particular), um dos principais fatores por trás dos projetos de integração física da América do Sul. Segundo os referidos autores, a IIRSA-COSIPLAN atende a uma lógica exploratória intensiva em território e formas patrimonialistas e rentistas de apropriação (do território), o que acaba por gerar conflitos. Nesse cenário, a vontade dos atores locais possui um forte adversário, haja vista que por trás dos projetos de infraestrutura da IIRSA-COSIPLAN estão grandes empresas privadas brasileiras que, na última década, espraiaram sua atuação por diversos países (HIRT, 2014). As grandes empresas utilizam o território em função dos seus próprios objetivos, muitas vezes desrespeitando o entorno econômico, social, político, cultural, moral ou geográfico, chegando, em alguns casos, a configurar um elemento de perturbação e desordem. (SANTOS, 2010).

Para Hirt (2014), as intencionalidades dos eixos da IIRSA-COSIPLAN estão ligadas a ações de exploração intensivas em território processos intolerantes com entes não mercantis. A implementação da iniciativa corrobora a ideia de que a territorialidade do capitalismo engendra a mercantilização até as últimas consequências, posto que a iniciativa vem sendo materializada em obras construídas de forma autoritária - rodovias, barragens, hidrelétricas e linhas de transmissão que geram, muitas vezes, indivíduos sem terra e sem teto.

Críticos à iniciativa, como Luce (2007), têm afirmado que o BNDES atua como agente econômico brasileiro no IIRSA-COSIPLAN ao projetar os interesses nacionais sob a retórica da integração sul-americana. Além disso, as empreiteiras brasileiras gozariam de uma reserva de mercado, visto que ao contar com o apoio do BNDES asseguram uma presença competitiva nas licitações pelos contratos das obras de infraestrutura. Por fim, ganhos de escopo também seriam contemplados na exigência de aquisição de máquinas e equipamentos brasileiros, beneficiando a indústria de bens de capital do país.

No que tange aos custos do processo de integração sul-americano, Paz (2015) questiona se o Brasil teria sido capaz de exercer o papel de paymaster da integração. A autora afirma ainda que não há consenso sobre os resultados da IIRSACOSIPLAN, sendo difícil dizer se houve ou não um aprofundamento da integração regional, haja vista a pouca transparência que envolve os projetos e o sigilo bancário no que tange aos contratos entre o BNDES e as empreiteiras executoras das obras.

\section{Obstáculos à projeção internacional do Brasil}

O Brasil possui objetivos internacionais ligados à sua inserção no Sistema Internacional como país de dimensões continentais com capacidade de desenvolver um crescimento autossustentado e de alcançar padrões mais elevados de riqueza e poderio nacional (BECARD, 2009).

No entender de Cervo (2003), o Brasil tem na América do Sul o espaço natural de afirmação de seus interesses. Espaço que poderia ser acrescido de países do Atlântico africano. Esta ideia foi abraçada pela diplomacia brasileira durante o governo Lula da Silva, quando a integração sulamericana e o fortalecimento político-institucional do MERCOSUL fizeram parte da estratégia de reforçar a coesão com os países vizinhos e expandir a projeção internacional do Brasil.

Por sua vez, Guimarães (2002) destaca que o Brasil precisa desenvolver suas exportações para mercados de alto poder aquisitivo, no entanto, historicamente o país tem esbarrado na reação do protecionismo antigo ou moderno, de setores que sofrem com a competição brasileira. Situação que vem ocorrendo em mercados do hemisfério Norte (leia-a Estados Unidos e União Europeia), onde o protecionismo é mascarado por trás de acusações de dumping ou subsídios, como atestam 
as barreiras contra a importação de aço, açúcar, calçados e suco de laranja made in Brazil.

As práticas protecionistas se desenvolvem não apenas em outros continentes como dentro do MERCOSUL, constituindo um sério obstáculo ao aprofundamento do bloco. Nesse sentido, Pereira (2009) destaca que o governo argentino passou a impor medidas protecionistas sob a alegação da necessidade de defesa de sua indústria, em virtude da assimetria com o Brasil. A essas práticas somam-se as listas de exceções à Tarifa Externa Comum (TEC), outro tema delicado no MERCOSUL. Previstas inicialmente para terminar entre 2015 e 2019, dependendo do país, as listas foram prorrogadas pela Decisão CMC n ${ }^{\circ}$ 26/15 e estarão vigentes até 2021 para Brasil e Argentina, até 2022 para Uruguai e Venezuela e até 2023 para o Paraguai. Dessa forma, os países do bloco seguirão autorizados a manter tarifas diferenciadas de importação para centenas de mercadorias produzidas fora do MERCOSUL.

Consideradas importantes pelos países membros, para acomodar temporariamente pressões internas, as listas de exceções simbolizam uma falha no projeto de união aduaneira. Em função da diferença de tributação, nas lojas de importados localizadas em municípios paraguaios de fronteira, como Ciudad del Este ou Pedro Juan Caballero, por exemplo, os produtos chegam, em média, a ser $30 \%$ mais baratos do que no lado brasileiro.

\section{Brasil: de líder regional a ator de importância reduzida no cenário internacional}

Para além dos obstáculos referentes a questões de tributação no âmbito do MERCOSUL, o Brasil vem atravessando desde 2014 um novo momento em sua política externa e vem reduzindo sua presença no cenário internacional. Esse novo momento teve início com a crise político-econômica instaurada no país e fortemente impactada pela Operação Lava Jato, da Polícia Federal.

O Relatório de Conjuntura $n^{\circ} 1$, produzido em maio de 2017 pela Secretaria-Geral da Presidência da República e pela Secretaria Especial de Assuntos Estratégicos, destaca que ao longo do governo Dilma Rousseff, o Brasil passou de um Estado que tinha uma das políticas externas mais ativas entre os países emergentes para um Estado paralisado pela crise e que não lidera mais os debates sobre o futuro da América Latina (BRASIL, 2017 b).

O cenário descrito no relatório se explica por alguns fatores: os erros de estratégia da presidente Dilma Rousseff; a crise econômica vivenciada pelo país (que também sofreu os efeitos da queda do preço do petróleo a partir de 2014); a Operação Lava Jato e; a crise política, que levou o vicepresidente Michel Temer ao poder.

A crise política e econômica interrompeu o projeto de Brasil potência, que havia sido impulsionado em 2006, com o anúncio feito pela Petrobras da descoberta de petróleo na camada do pré-sal ${ }^{6}$ e que tomou fôlego a partir de 2008, após a confirmação da descoberta, quando o preço internacional do petróleo atingiu seu ápice, na cotação de quase U\$140 por barril. Nesse período (anos do segundo governo Lula da Silva) o Brasil estava voltado para a expansão internacional.

O pré-sal também despertou o interesse dos EUA, que reativaram a Quarta Frota (uma divisão da Marinha estadunidense que só havia funcionado entre 1943 e 1950) no Atlântico Sul em abril de 2008. Além disso, a presidente Dilma Rousseff e estatais brasileiras foram vítimas de espionagem realizada pela NSA, a Agência de Segurança Nacional dos Estados Unidos (BRASIL, 2017 b). A partir de 2014, a queda abrupta no preço do barril de Brent (gráfico 1), influenciada pelos EUA e pela OPEP, impactou fortemente as economias exportadoras de petróleo e enfraqueceu a atuação do Brasil no cenário internacional.

Em junho de 2014, o barril tipo Brent era negociado a US\$115. Em janeiro de 2016 o preço havia caído para cerca de US\$30. Entre os principais motivos estão: o aumento da produção

IIIIIIIIIIIIIIIIIIIIIIIIIIIIIIIIII

6 A camada pré-sal corresponde a uma camada de rochas localizada abaixo de uma camada de sal. Entre a África e a América do Sul existe um depósito de matéria orgânica que se acumulou ao longo de milhões de anos sob o sal prensado por pesadas lâminas, transformando-se em petróleo. 
Gráfico 1. Variação do preço em dólar do barril de Brent cru (2007-2015).

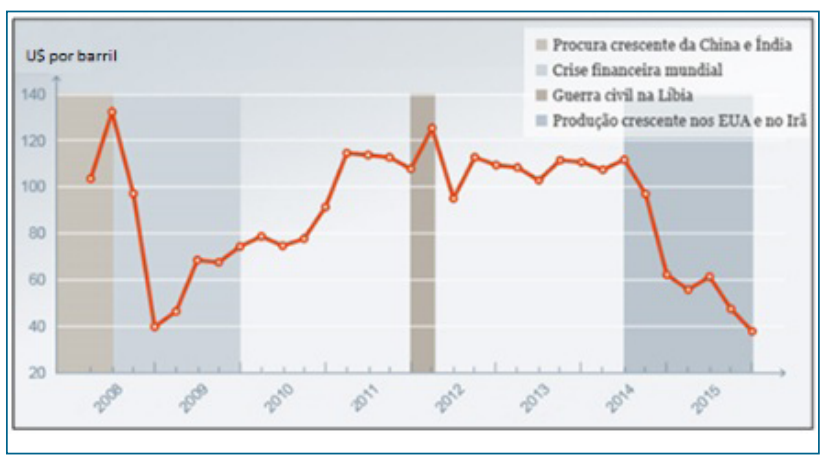

Fonte: US Energy Information Administration; DW, 2016.

de hidrocarbonetos (óleo de xisto) por parte dos EUA, que entre 2012 e 2015, elevaram sua produção de 10 para 14 milhões de barris por dia e tornaram-se o maior produtor mundial; e a falta de ação da OPEP, cujos membros poderiam ter cortado a produção para aumentar os preços, mas não o fizeram.

O Brasil sofreu os efeitos da queda do preço do petróleo no mercado internacional. O petróleo bruto configura uma commodity de importância estratégica para o país e, como já mencionado, está entre os principais produtos de exportação do Brasil. Além de marcar o início da forte queda no preço internacional do petróleo, o ano de 2014 também testemunhou o início da Operação Lava Jato, da Polícia Federal, a maior investigação de corrupção e lavagem de dinheiro já ocorrida no Brasil (batizada em virtude de ter começado num posto de rede de combustíveis e lava jato de veículos). A operação revelou um esquema de corrupção composto pelo cartel de empreiteiras que faziam parte do projeto de "Brasil potência".

Segundo as investigações, o esquema de cartel envolveu 23 empreiteiras que deveriam concorrer entre si, mas forjavam uma concorrência aparente que envolvia pagamento de propina a executivos e superfaturamentos em contratos. Segundo laudo da Polícia Federal, os prejuízos decorrentes apenas do cartel que se instalou contra a Petrobras foram de cerca de $\mathrm{R} \$ 42$ bilhões (MPF, 2017). O esquema de corrupção levou à cadeia diretores das empreiteiras e políticos de diversos partidos políticos, além causar a destituição de ministros e membros do legislativo.
Em 2017, três anos após o início da Lava Jato, as gigantes da construção encolheram e perderam o posto de protagonistas na economia brasileira. Impactadas pela operação e pela crise, as grandes empreiteiras começaram a demitir, venderam ativos e passaram a ficar de fora de concessões. Em alguns casos chegaram até mesmo a pedir recuperação judicial. Empresas como Odebrecht, Andrade Gutierrez, Camargo Corrêa e Engevix, que antes da Lava Jato investiam na diversificação de negócios para além da construção civil saneamento, indústria naval, aeroportos, etc. - mudaram de postura. A preocupação passou a ser a sobrevivência e não mais o crescimento da empresa. (LAPORTA; TREVISAN, 2017).

As investigações permaneceram após a vitória da presidente Dilma Rousseff nas eleições de 2014. O resultado das urnas provocou a reação da oposição, que se empenhou em sabotar o governo eleito e conseguiu promover, com o auxílio da grande mídia e do judiciário, um polêmico processo de impeachment (considerado um golpe parlamentar por intelectuais como Luiz Carlos Bresser-Pereira) que resultou no afastamento da presidente eleita e na posse do vice-presidente Michel Temer.

O novo governo capitaneado por Michel Temer anunciou um conjunto de medidas neoliberais e $o$ retorno à velha política de alinhamento aos EUA. Nomeado por Temer como ministro das Relações Exteriores, José Serra (autor do projeto de lei que fez a Petrobras deixar de ser a operadora única do pré-sal, abrindo-o às empresas estrangeiras), anunciou que a política externa do Brasil daria uma guinada na direção de um modelo de orientação neoliberal, voltado aos clássicos aliados econômicos: Estados Unidos, Europa e Japão.

O governo Temer marcaria ainda o fim da política industrial do país - a Petrobras passaria a comprar o que antes fabricava - e o desmonte do parque naval brasileiro. Todavia, mergulhado em escândalos de corrupção, o governo Temer deixou a política externa em segundo plano, voltando todos os esforços para sua própria sobrevivência (em meio aos inúmeros escândalos de corrupção envolvendo o presidente e ministros de seu governo 
que passaram a ocupar quase que diariamente as manchetes de jornais e os noticiários de tv).

Em meio à conjuntura interna, houve uma perda de qualidade na política exterior e a consequente perda de prestígio internacional do Brasil (BRASIL, 2017 b). De acordo com o Relatório de Conjuntura $\mathrm{n}^{\circ} 1$, o cenário para os próximos anos é de incerteza e a política externa brasileira, que deveria traduzir os interesses do país na arena internacional, mostra-se desprovida de um norte. (BRASIL, 2017b).

\section{A China como nova protagonista na integração sul-americana}

De acordo com Jaeger (2017), atualmente a China se faz presente em grandes projetos de energia, transportes e comunicações desenvolvidos em praticamente todas as regiões do globo. Em relação ao Brasil e à América do Sul, tais investimentos podem ser entendidos como um novo padrão de dependência centro-periferia.

Em meio à crise político-econômica vivida pelo Brasil, a China passou a ampliar os investimentos no país, sobretudo em setores como energia, infraestrutura e agronegócio. De acordo com a Câmara de Comércio e Indústria Brasil-China, empresas chinesas anunciaram para 2017 investimentos de U\$ 20 bilhões para a compra de ativos brasileiros, o que faz do Brasil o segundo destino de investimentos da China na área de infraestrutura, atrás apenas dos EUA. (PEREIRA, SCARAMUZZO, BORGES, 2017).

Por outro lado, as dificuldades do Brasil em aumentar sua participação no mercado chinês permanecem. Antes mesmo da crise políticoeconômica, Becard (2009) já identificava uma série de entraves para empresas brasileiras exportarem para a China. Tais dificuldades estariam relacionadas à infraestrutura deficiente e à excessiva carga tributária presentes no Brasil, mas também à forte concorrência no mercado chinês, à capacidade de poucos setores produtivos (soja e minérios) expandirem a oferta e à oscilação no preço das commodities.
Essa visão é corroborada por Cervo e Bueno (2008), que entendem que, com exceção de alguns bens primários, os produtos brasileiros não chegam ao mercado chinês em quantidade desejável. Por outro lado, existem obstáculos que dificultam a penetração de empresas chinesas no território brasileiro, a saber: exigência de licenças ambientais, burocracia excessiva, legislação trabalhista, carga tributária e dificuldade de obtenção de vistos. Ainda assim, apesar de todos esses entraves, em 2015 a China foi o principal parceiro comercial do Brasil.

Cabe destacar que, além do Brasil, que em 2015 respondeu por $75 \%$ das exportações agrícolas da América Latina à China, o país asiático mantém interesses em outros Estados sul-americanos. Caso de Argentina, Chile e Uruguai, que junto com o Brasil responderam por $98 \%$ das exportações agrícolas latino-americanas à China em 2015. (JAEGER 2017).

Nos últimos anos, a liderança brasileira no processo de integração sul-americana vem sofrendo uma retração e esse vácuo deixado pelo Brasil está sendo aproveitado pela China, que percebe na região um grande potencial não aproveitado para investimentos. De acordo com Jaeger (2017), em termos geopolíticos e geoestratégicos, a China nutre interesse no controle sobre infraestruturas sul-americanas, haja vista que o acesso à infraestrutura garante maior autonomia na exploração de recursos estratégicos (minérios, alimentos, energia, água, etc.).

Os investimentos chineses em infraestrutura na América do Sul visam o aumento da segurança e a eficiência do transporte e do escoamento de commodities ao país asiático. A presença chinesa na região já se faz notar pelas represas Néstor Kirchner e Jorge Cepernic, na Argentina, pela participação no leilão de Libra (área do pré-sal), no Brasil, pelo metrô de Quito, no Equador, pela modernização de portos na Venezuela, na Colômbia, na Argentina e no Chile, assim como pelo projeto da Ferrovia Bioceânica ou Transcontinental Brasil-Peru. (JAEGER, 2017). 
A China necessita de recursos naturais para sustentar sua expansão econômica e tem interesse na construção de projetos ferroviários em outras regiões do globo. No que tange ao projeto da Ferrovia Bioceânica (mapa 2), estudos técnicos já foram iniciados em solo brasileiro para ligar o porto de Açu, no Rio de Janeiro, a Porto Velho, em Rondônia. A nova rota para o Pacífico possibilitaria aos produtores brasileiros uma alternativa para o envio de matérias-primas para a China. Com custo estimado em até US $\$ 10$ bilhões (cerca de $\mathrm{R} \$ 30$ bilhões), a construção da ferrovia marcaria uma nova fase na relação da China com a América do Sul. No entanto, para que o projeto saia do papel será necessário superar grandes desafios de engenharia, ambientais e políticos.

A presença chinesa na infraestrutura da América do Sul configura um cenário de desafios e oportunidades. No entanto, os sul-americanos correm o risco de que setores estratégicos, como o de energia elétrica, fiquem sob controle de empresas chinesas. Em 2016, a estatal chinesa State Grid comprou da Camargo Corrêa, atingida pela Operação Lava Jato, o controle da maior empresa privada do setor no Brasil, a CPFL Energia. No Brasil desde 2010, a State Grid já possui 7,6 mil km de linhas de transmissão em operação e 9,8 mil km em construção, o que corresponde a cerca de $20 \%$ de toda a rede elétrica brasileira. (POLITO, 2016).

Além do controle de setores estratégicos, também existe o risco de que a indústria local sofra com a concorrência asiática. Em meio ao cenário de crise, enfraquecido economicamente e politicamente, o Brasil não demonstra hoje condições de liderar os esforços para que os ganhos do relacionamento da América do Sul com a China sejam mútuos de fato e fortaleçam a integração regional.

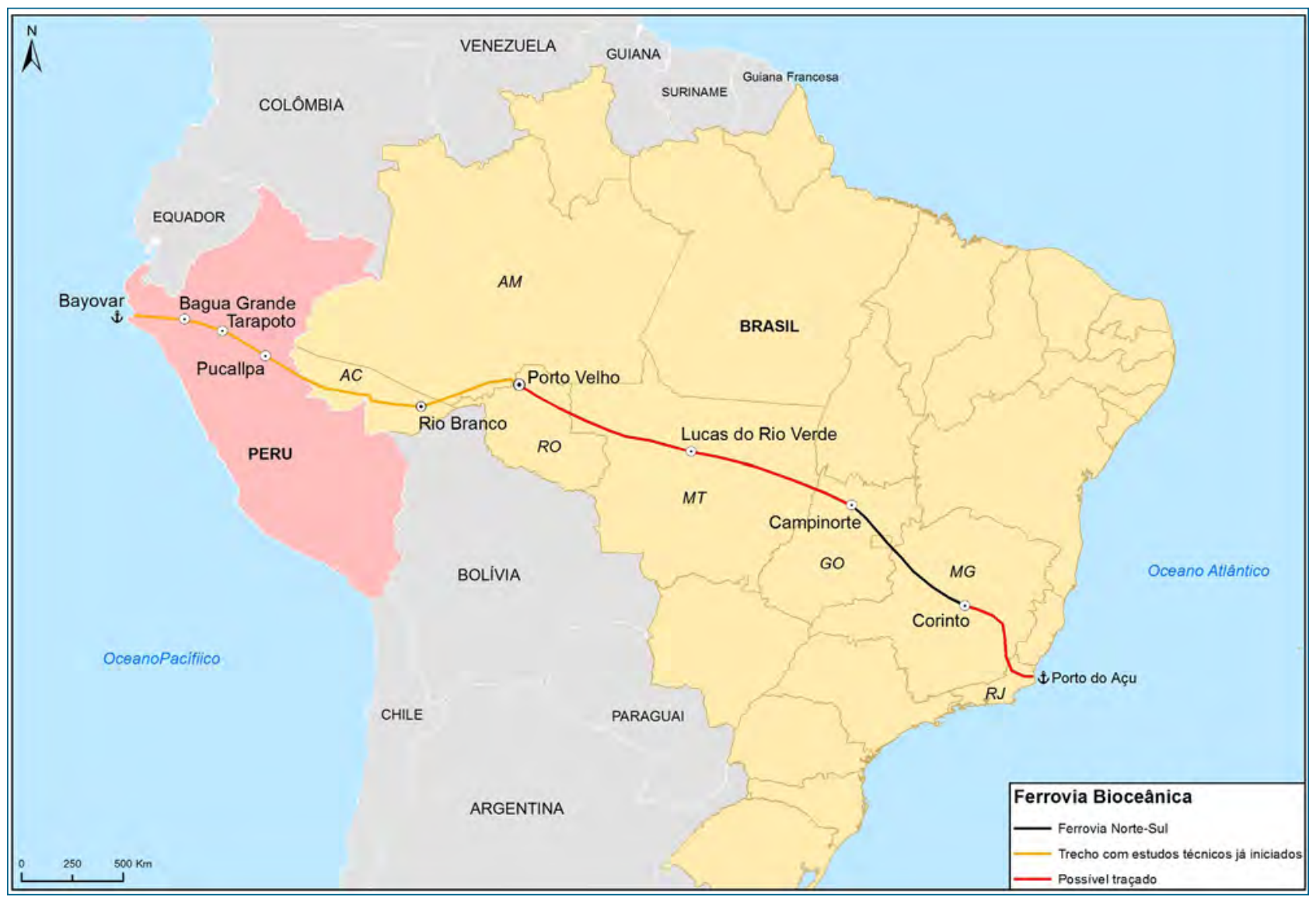

Autor: Camilo Pereira Carneiro, 2017. 


\section{Considerações finais}

Comumente, questões de integração ou cooperação na América do Sul são apresentadas por meio de vieses antagônicos: a) de um lado, uma visão otimista, "estamos avançando, as dificuldades são naturais", se a integração comercial e produtiva não progride, há outros campos a desenvolver, nos âmbitos social, cultural, político, etc.; b) de outro, uma visão pessimista, segundo a qual o MERCOSUL e outros acordos são apresentados como barreiras que impossibilitam que o Brasil se insira na economia mundo e participe de acordos de maior magnitude.

Todavia, face à conjuntura política e econômica atual, é possível afirmar que diminuíram significativamente as chances de o Brasil retomar em curto prazo o protagonismo na América do Sul. Após exercer grande influência nos mandatos dos ex-presidentes Fernando Henrique Cardoso e Luiz Inácio Lula da Silva, o Itamaraty perdeu prestígio no governo da presidente Dilma Rousseff. A política externa, que já não era tida como prioridade, sobretudo a partir do segundo mandato da presidente, com o agravamento da crise interna e a posse do presidente Michel Temer passou a receber ainda menos importância (haja vista a preocupação do presidente em direcionar todos os esforços para se manter no poder).

A política externa brasileira no governo Temer praticamente desapareceu. O Brasil recuou na América do Sul, assim como na sua política internacional. O Itamaraty passou a fazer uma política externa de baixo perfil e de desengajamento, que fez o país perder peso no cenário internacional. Dessa forma, o Brasil deixou de atuar como um vetor do processo de integração na América do Sul, abrindo espaço para potências extrarregionais como a China. Com o PSDB no comando do Itamaraty houve um redirecionamento da política externa, que passou a privilegiar o bilateralismo em prejuízo dos fóruns multilaterais. Além disso, ao se alinhar aos interesses das grandes potências, o governo Temer provocou uma ruptura em relação a uma política externa altiva, que foi realizada, sobretudo, entre
2003 e 2014, período em que o Brasil privilegiou as relações Sul-Sul.

Sob o governo Temer, o Ministério de Relações Exteriores passou a se caracterizar por uma agenda vazia e por uma diplomacia financeira, com reduzidas e desprestigiadas viagens, destinadas a demonstrar aos investidores estrangeiros que o país está estável e vem retomando o crescimento econômico. Essa falta de norte na política externa chegou a ser reconhecida no Relatório de Conjuntura $\mathrm{n}^{\circ} 1$, um documento produzido pelo próprio governo.

\section{Referências}

ALMEIDA, Paulo Roberto de. Os primeiros anos do século XXI. O Brasil e as Relações Internacionais Contemporâneas. São Paulo: Paz e Terra, 2002. 282 p.

ALVARENGA, Darlan; GAZZONI, Marina. Com ajuda do BNDES, donos da JBS criaram maior empresa de carnes do mundo. In: G1, 18. mai. 2017. Disponível em <http:// g1.globo.com/economia/negocios/noticia/com-ajuda-dobndes-donos-da-jbs-criaram-maior-empresa-de-carnesdo-mundo.ghtml>. Acesso em: 9 jul. 2017.

AVISITE. Exportação brasileira: 10 principais produtos da pauta - janeiro-dezembro de 2015. Disponível em < http://www. avisite.com.br $>$. Acesso em: 11 jul. 2017.

BECARD, Danielly Silva Ramos. Relações Exteriores do Brasil contemporâneo. Petrópolis: Vozes, 2009. 223 p.

BORGES, Renato Thomaz. O Novo Regionalismo na América do Sul: A Formação de um Sistema de Poder. In: Revista NEIBA - Cadernos Argentina-Brasil, vol. III, $\mathrm{n}^{\circ} 1$, nov. 2014, pp. 11-21.

BRASIL. Ministério das Relações Exteriores. União de Nações Sul-Americanas. Disponível em <http://www.itamaraty. gov.br>. Acesso em: 12 jun. 2017a.

BRASIL. Secretaria-Geral da Presidência da República e Secretaria Especial de Assuntos Estratégicos. Relatório de Conjuntura $n^{\circ} 1$ - Brasil: um país em busca de uma grande estratégia. Disponível em <http://arte.folha.uol.com. br/mundo/2017/06/01/relatorio.pdf>. Acesso em: 10 jul. 2017b.

CABALLERO, Bernardino H. Saguier. El Paraguay y la Integración Sudamericana. In: A América do Sul e a Integração Regional. Wehling, Arno; Pimentel, José Vicente de Sá (orgs.). Brasília: FUNAG, 2012, pp. 103-118.

CERVO, Amado Luiz. Política exterior e relações internacionais do Brasil: enfoque paradigmático. Revista Brasileira de Relações Internacionais, 46 (2), 2003, p. 5-25.

CERVO, Amado Luiz; BUENO, Clodoaldo. História da política exterior do Brasil. $3^{a}$ edição. Brasília: Editora UnB, 2008. $560 \mathrm{p}$.

COSIPLAN. Foro técnico IIRSA. Disponível em < http://www. iirsa.org>. Acesso em: 20 mai. 2017a. 
COSIPLAN. Ejes de integración y desarrollo. Disponível em $\langle$ http://www.iirsa.org/infographic $>$. Acesso em: 22 mai. 2017b.

DUARTE, Rosario Santa Gadea. Oportunidades y desafíos de la Integración Sudamericana: una perspectiva Andina. In: A América do Sul e a Integração Regional. Wehling, Arno; Pimentel, José Vicente de Sá (orgs.). Brasília: FUNAG, 2012, pp. 157-189.

GARCIA, Eugênio Vargas. Cronologia das Relações Internacionais do Brasil. $2^{a}$ edição. Rio de Janeiro: Contraponto, 2005. $336 \mathrm{p}$.

GLOBAL FIREPOWER. Countries Ranked by Military Strength (2016). Disponível em <http://www.globalfirepower.com/ countries-listing.asp >. Acesso em: 25 abr. 2017.

GUIMARÃES, Samuel Pinheiro. Quinhentos anos de periferia. Porto Alegre: Editora da UFRGS, 2002.166 p.

GUIMARÃES, Samuel Pinheiro. A perspectiva brasileira da integração sul-americana. In: A América do Sul e a Integração Regional. Wehling, Arno; Pimentel, José Vicente de Sá (orgs.). Brasília: FUNAG, 2012, 93-96.

HIRT, Carla. O BNDES, o desenvolvimento e o grande capital nacional: uma análise escalar e territorial. Revista de Geografia, vol. 31, n 2, 2014.

JAEGER, Bruna Coelho. Investimentos chineses em infraestrutura na América do Sul: impactos sobre a integração regional. Revista Conjuntura Austral, vol. 8, n 39-40, pp. 4-23, dez. 2016/mar. 2017.

LAPORTA, Taís; TREVISAN, Karina. Empreiteiras encolheram e perderam protagonismo na economia após Lava Jato. In: G1. Disponível em <http://g1.globo.com/economia/ negocios/noticia/empreiteiras-encolheram-e-perderamprotagonismo-na-economia-apos-lava-jato.ghtml>. Acesso em 10 jul. 2017.

LUCE, Mathias Seibel. O subimperialismo brasileiro revisitado: a política de integração regional do governo Lula (2003-2007). Dissertação (Mestrado em Relações Internacionais). Porto Alegre: UFRGS, 2007.

MONIZ BANDEIRA, Luiz Alberto de Vianna. O Brasil como potência regional e a importância estratégica da América do Sul na sua política exterior. Revista Espaço Acadêmico $\mathrm{n}^{\circ}$ 91, dez. 2008.

MPF. Ministério Público Federal. Procuradoria da República no Paraná. Força Tarefa "Operação Lava Jato". Inquérito Policial n 5006597-38.2016.4.04.7000. Denúncia apresentada em 22 mai. 2017. Disponível em <http:// www.mpf.mp.br/pr/sala-de-imprensa/docs/denuncialula-sitio-de-atibaia>. Acesso em 12 jun. 2017.

OEC. The Observatory of Economic Complexity: Brazil. Disponível em: <http://atlas.media.mit.edu/en/profile/ country/bra/>. Acesso em: 20 jun. 2017.

PAZ, Gabriele S. Integração da América do Sul: o BNDES como agente da política regional do governo Lula. In: Anais do $1^{\circ}$ Seminário Internacional de Ciência Política. Estado e democracia em mudança no século XXI. Porto Alegre: UFRGS, 2015.

PEREIRA, Lia Valls. Brasil-Argentina: o protecionismo de reciprocidade. Revista Conjuntura Econômica, vol. 63 , n ${ }^{\circ}$ 11, 2009, pp. 76-79.

PEREIRA, René; SCARAMUZZO, Mônica; BORGES, André. Nova onda de investimentos chineses deve trazer U\$ 20 bi para o Brasil. Estadão, 19 mar. 2017. Disponível em <http://economia.estadao.com.br/noticias/geral,novaonda-de-investimentos-chineses-deve-trazer-us-20-bipara-o-brasil,70001705110 >. Acesso em 10 jul. 2017.

PEREIRA CARNEIRO, Camilo. Fronteiras irmãs: transfronteirizações na Bacia do Prata. Porto Alegre: Ideograf, 2016. 273 p.

POLITO, Rodrigo. State Grid vai criar nova distribuidora no Brasil. Valor Econômico, 10 out. 2016. Disponível em <http://www.valor.com.br/empresas/4739531/stategrid-vai-criar-nova-distribuidora-no-brasil $>$. Acesso em: 9 jul. 2017.

PORTO-GONÇALVES, Carlos Walter; QUENTAL, Pedro de Araújo. Colonialidade do poder e os desafios da integração regional na América Latina. Polis. Revista Académica de La Universidad Bolivariana de Chile, vol. 31, p. 16, 2012.

RODRIGUEZ, Paloma. BNDES financiou R $\$ 14$ bi para empreiteiras realizarem obras no exterior. Poder $360,1^{\circ}$ fev. 2017. Disponível em <http://www.poder360.com. br/governo/bndes-financiou-r-14-bi-para-empreiteirasrealizarem-obras-no-exterior/>. Acesso em: 8 jul. 2017.

SANTOS, Milton. Por uma outra globalização: do pensamento único à consciência universal. 19a edição. São Paulo: Record, 2010. $174 \mathrm{p}$.

SCHEIBE, Eduarda. Integração física e integração regional: a Iniciativa para Integração da Infraestrutura regional Sul-Americana (IIRSA/COSIPLAN) como instrumento multiescalar de integração. Dissertação (Mestrado em Geografia). Porto Alegre: UFRGS, 2013.

SCHMIED, Julie. Cenários da integração regional: os desafios da União de Nações Sul-americanas (UNASUL) - o novo caminho da integração na América do Sul. In: União Européia e Mercosul: dois momentos especiais da integração regional. Rio de Janeiro, Fundação Konrad Adenauer, Cadernos Adenauer VIII, nº 1, 2007, pp. 105126.

VIGEVANI, Tullo; CEPALUNI, Gabriel. A Política Externa de Lula da Silva: a estratégia da autonomia pela diversificação. Rio de Janeiro, vol. 29, n² 2, jul./dez. 2007, p. 273-335. Disponível em: <http://www.scielo.br/pdf/cint/v29n2/ v29n2a02>. Acesso em: 17 jun. 2017. 


\section{Camilo Pereira Carneiro}

Doutor em Geografia, professor visitante do Programa de Pós-Graduação em Fronteiras e Direitos Humanos da Universidade Federal da Grande Dourados. Pesquisador do grupo LABETER (Laboratório Estado e Território da UFRGS). Autor do livro Fronteiras irmãs: transfronteirizações na Bacia do Prata. Linhas de pesquisa: fronteiras, geografia política, conflitos internacionais e cartografia temática. E-mail: pereiracarneiro.camilo@gmail.com

\section{Milene Meneghetti Bruhn}

Discente do Curso de Graduação em Relações Internacionais da UFRGS (Universidade Federal do Rio Grande do Sul). Suas linhas de pesquisa são: fronteiras, cooperação transfronteiriça na América do Sul, geografia política e conflitos internacionais. E-mail: milenebruhn@gmail.com 